\title{
Rotating night shift work, exposure to light at night, and glomerular filtration rate: baseline results from a Chinese occupational cohort
}

\section{Shengkui Zhang}

North China University of Science and Technology https://orcid.org/0000-0003-0859-6884

\section{Yongbin Wang}

Xinxiang Medical University

\section{Zhende Wang}

North China University of Science and Technology

Han Wang

North China University of Science and Technology

\section{Chao Xue}

North China University of Science and Technology

Qinglin Li

North China University of Science and Technology

Xiaoming Li

North China University of Science and Technology

\section{Weijun Guan}

North China University of Science and Technology

Juxiang Yuan ( $\square$ yuanjxncst@163.com )

https://orcid.org/0000-0003-4968-7387

\section{Research}

Keywords: renal function, light at night, night shift work, steelworkers

Posted Date: March 26th, 2020

DOl: https://doi.org/10.21203/rs.3.rs-19446/v1

License: (c) (i) This work is licensed under a Creative Commons Attribution 4.0 International License. Read Full License 


\section{Abstract}

Background The misalignment between the circadian clock and behavioral cycles has been implicated in pathogenesis of many diseases. However, whether the kidneys are also more prone to disease in the circumstances of chronic circadian rhythms disruption due to night shift work and light at night (LAN) is unclear. The main purpose of this study is to examine the association between rotating night shift work, exposure to light at night, and glomerular filtration rate among steelworkers in north China.

Methods A total of 6869 participants, aged 22 to 60 years, were included in this study. Multivariable logistic regression was used to examine the association between night shift work, the brightness of bedroom ambient light at night (LAN), and estimated glomerular filtration rate (eGFR) with adjustment for potential confounders. The relationship between duration of night shift work (continuous), cumulative number of night shifts (continuous), and eGFR were also examined using restricted cubic spline models.

Results Long duration of night shift work ( $\geq 29$ years) had elevated odds of decreased eGFR (OR, 1.39, $95 \% \mathrm{Cl} 1.10-1.75)$ compared with day work after adjustment for potential confounders. Negative associations between duration of night shift work, cumulative number of night shifts, and eGFR $(\mathrm{mL} / \mathrm{min} / 1.73 \mathrm{~m} 2)$ were observed in RCS models. No significant associations were observed among the different brightness of bedroom ambient light levels: middle level (OR, 0.90,95\% $\mathrm{Cl} 0.77-1.05)$, lightest level (OR, 0.94, 95\% $\mathrm{Cl} 0.75-1.17)$, and decreased eGFR compared with the darkest level.

Conclusion The increased duration of night shift work and cumulative number of night shifts among night shift workers, but not the brightness of bedroom ambient LAN, are associated with a slight decline of renal function among steelworkers.

\section{Introduction}

To maximize economic and societal benefit, modern society is depended on a 24 hours schedule. In this circumstance, rotating night shift work and exposure to artificial light at night (ALAN) have become commonplace, even though its negative impact on health has been shown in a considerable body of evidence from epidemiological and experimental studies [1]. Approximately $20 \%$ of workers in industry countries are engaged in a shift work schedule [2]. In addition to the night shift work, which inevitably exposes workers to LAN during their working hours, ALAN in the daily life has become a widespread environmental pollutant. It is estimated that $23 \%$ of the land surface experienced ALAN [3], and this exposure is increasing about $6 \%$ per year [4]. Moreover, the trend of exposure to night shift work and LAN parallels the increase in the percentage of patients with chronic kidney disease in China [5].

Several renal functions, including glomerular filtration rate, have circadian rhythms $[6,7]$. Since the mid19th century, circadian rhythms of most renal functions have been published [6]. The discovery of its molecular mechanism, circadian clock, which has been recognized with the awarding of the Nobel Prize in Physiology and Medicine in 2017, has rendered the study of renal circadian to a new era [8]. Misalignment between behavioral, such as altered meal timing and sleep displacement, and molecular 
circadian clocks due to night shift work may increase the risk of type 2 diabetes [9, 10], obesity [11] and cardiovascular disease [12]. Moreover, according to the latest evaluation of the carcinogenicity of night shift work in 2019, the International Agency for Research on Cancer (IARC) has classified night shift work in Group 2A, "probably carcinogenic to humans", based on limited evidence of cancer in humans, sufficient evidence of cancer in experimental animals, and strong mechanistic evidence in experimental animals [13]. Furthermore, asynchrony between circadian clocks and external world light/dark cycle due to LAN has associated with breast and prostate cancer [14], metabolic dysfunction [15] and cardiovascular disease [16]. However, whether the chronic disruption of circadian rhythms due to LAN and night shift work is responsible for the development of kidney disease remains unclear. To the best of our knowledge, there is currently no other study to examine the relationship between rotating night shift work, exposure to light at night, and eGFR based on a large-scale population. The aim of this study is to explore whether rotating night shift work and exposure to bedroom ambient LAN are associated with renal function.

\section{Methods}

\section{Study Design and Population}

This study reported results from the baseline survey conducted among steelworkers who were prospectively recruited at eleven steel production departments in north China[17]. All workers at this company underwent a legally required health examination each year. A total of 7661 participants were recruited from February to June, 2017. After excluding 390 participants without detailed information on current shift work status, 104 without brightness of bedroom ambient LAN, 43 without serum creatinine, and 255 with incomplete information on covariates, 6869 participants were included in this study (Figure 1). Compared with participants included, those who were excluded were older ( $44.2 \pm 8.0$ years versus $34.3 \pm 7.6$ years, $P<0.001$ ). Among the 6869 included participants, $91.5 \%$ were male workers (versus $93.7 \%$ among excluded, $P=0.032$ ). All participants gave informed consent before taking part in this study.

\section{Assessment of GFR}

Blood was drawn from the participant's forearm venous between 08:00 and 09:30 after they have fasted for 12 hours. For night shift workers, blood was drawn in the morning of a day off work. Sarcosine oxidase method was used to test serum creatinine (CRE kit, Beijing Strong Biotechnologies, Inc., Beijing, China). Within-laboratory intra-and inter-assay variable coefficients for serum creatinine were $<6 \%$ and $<8 \%$, respectively. Assessment of eGFR was based on the Chronic Kidney Disease Epidemiology Collaboration (CKD-EPI) equation [18]. The CKD-EPI formula is as follows: eGFR $\left(\mathrm{mL} / \mathrm{min} / 1.73 \mathrm{~m}^{2}\right)=141$ $\times \min (\mathrm{Scr} / K, 1)^{\mathrm{a}} \times \max (\mathrm{Scr} / K, 1)^{-1.209} \times 0.993^{\mathrm{Age}} \times(1.018$ if female $) \times(1.159$ if black $)$. Scr indicates serum creatinine $(\mu \mathrm{mol} / \mathrm{L}), k=0.7$ for females and 0.9 for males, $a=-0.329$ for females and -0.411 for males, min and max indicate the minimum of Scr/ $k$ or 1 , the maximum of $\mathrm{Scr} / k$ or 1 , respectively. According to the Kidney Disease Improving Global Outcomes 2012 recommendations, the range of GFR $\left(\mathrm{mL} / \mathrm{min} / 1.73 \mathrm{~m}^{2}\right)$ was classed into five categories: normal or high (GFR $\left.\geq 90, \mathrm{G} 1\right)$, mildly decreased 
(GFR: $60-89, G 2)$, mildly to moderately decreased (GFR: $45-59, \mathrm{G} 3 \mathrm{a})$, moderately to severely decreased (GFR: $30-44, G 3 b)$, severely decreased (GFR: 15-29, G4), and kidney failure (GFR < 15, G5) [19]. Based on this classification criteria, only $22(0.3 \%)$ participants had eGFR<60 mL/min $/ 1.73 \mathrm{~m}^{2}$ (G3a-G5), so we combined these categories into $\mathrm{G} 2$ in the subsequent analysis and defined them as "decreased eGFR".

\section{Assessment of shift work}

Shift work in this study refers to rotating night shift work (mainly four-crew-three-shift system now). In the four-crew-three-shift system, each group has two morning-shifts (08:00-16:00), two afternoon-shifts (16:00-00:00), two night-shifts (00:00-08:00), and was then off-duty for two days. In this study the detailed lifetime employment history was collected by face-to-face personal interviews. Participants recruited were asked to report whether they were involved in rotating night shift work (working through 00:00 to 6:00) during their employment [20]. If yes, they would be further asked about the start and end dates of each shift system, the average number of night shifts per month in each shift system, and usual days off per month. All the reported information was verified with the company's records. "Day work" indicates workers who always worked regular working hours (8:00 to 16:00). Using the above work schedule information, the duration of night shift work (years) (sum of years spent in all jobs including night shift work) and cumulative number of night shifts (nights) (sum of nights spent in all jobs including night shifts) were aggregated [21].

\section{Assessment of bedroom light environment}

Exposure to LAN was assessed through participants' report about the brightness of the bedroom ambient at night. Participants were asked to class the brightness of their bedroom LAN into the following four categories: "you wear a mask or too dark to see your fingers"; "light enough to see your fingers but not to identify the indoor environment clearly"; "light enough to identify the indoor environment clearly but not enough to read", "light enough to read". The last two categories were merged due to the small number of the last brightest category (2.01\%), and then the exposure level was divided into "darkest", "middle", "lightest" according to the brightness. The participants were also asked to report the usual times light on per night [22].

\section{Assessment of covariates}

Covariates mainly include age, sex, body mass index (BMI), ethnicity, smoking status, drinking status, educational level, physical activity, sleep duration, insomnia, diabetes, dyslipidemia, and elevated blood pressure. (see supplementary appendix)

\section{Statistical analysis}

Continuous variables are presented as means and standard deviations, and between-group comparisons were performed using Student's t test if the data were normally distributed. Otherwise, the median (upper quartile-lower quartile) and Wilcoxon Scores (Rank Sums) test were used to describe and compare these 
continuous variables between groups. Initial bivariate associations between eGFR and potential confounders were also assessed with Pearson's correlation $(r)$ or Spearman's rank correlation $\left(r_{s}\right)$ for continuous variables according to its distribution characteristics. Categorical variables are presented as numbers and percentages, and the chi-square test was used to compare differences among groups.

Multivariate logistic regression models were used to examine the relationships between night shift work, the brightness of bedroom ambient, and decreased eGFR. Restricted cubic spline models were utilized to visually examine the association between duration of night shift work (continuous), cumulative number of night shifts (continuous), and eGFR (as a continuous variable and a categorical variable, respectively) with adjustment for potential confounders.

Subsequently, in subgroup analysis we introduced multiplicative interaction terms using duration of night shift work in quartiles and the stratifying factors including sex, BMI $\left(<25\right.$, or $\left.\geq 25 \mathrm{~kg} / \mathrm{m}^{2}\right)$, bedroom ambient light level (darkest level/ middle or lightest level), diabetes (no/yes), hypertension (no/yes), dyslipidemia (no/yes), insomnia (no/yes), and short sleep duration (no/yes) to assess potential effect modification. Log likelihood ratio test was used to compare models with and without cross-product interaction terms. $P<0.05$ was regarded as significant for 2-sided tests. All statistical analyses were performed using SAS 9.3 (SAS Institute Inc., Cary, NC, USA).

\section{Results}

\section{General characteristics of the participants}

The baseline characteristics according to the eGFR status are shown in Table 1. The present study of 6869 included participants consisted of $91.5 \%$ males, with a mean age of 44.2 years, a mean BMI of 25.2 $\mathrm{kg} / \mathrm{m}^{2}$, and a mean eGFR of $101.7 \mathrm{~mL} / \mathrm{min} / 1.73 \mathrm{~m}^{2}$. Approximately $85 \%$ participants current or ever engaged in night shift work. $11.8 \%$ of participants reported a lightest brightness of bedroom ambient LAN. $25.6 \%$ of participants with elevated blood pressure and $10.5 \%$ with diabetes. The prevalence of decreased eGFR in the present study population showed a positive association with the duration of night shift work, with the prevalences in day workers, Q1 (1-12 years), Q2 (13-20 years), Q3 (21-28 years), and Q4 (29-43 years) being $13.2 \%, 15.3 \%, 16.6 \%, 21.0 \%$, and 34.0\%, respectively. The basic characteristics of participants according to shift work status are shown in Additional file 2: Table S1. The prevalence of decreased eGFR in male workers was significantly higher than that in female workers (Additional file 2: Table S2). eGFR was correlated with BMI $(r=-0.053, P<0.001)$, sleep duration $(r=0.063, P<0.001)$, fasting blood glucose $\left(r_{\mathrm{s}}=-0.123, P<0.001\right)$, systolic $(r=-0.136, P<0.001)$ and diastolic blood pressure $(r$ $=-0.167, P<0.001)$, duration of night shift work $(r=-0.201, P<0.001)$.

\section{Night shift work, LAN, and eGFR}

Multivariate adjusted ORs between night shift work, LAN, and decreased eGFR are shown in Table 2. Compared with day work, significant increased odds ratios of decreased eGFR were observed in the higher exposure groups of "duration of night shift work (years)" among night shift workers ( $P$ trend 
$<0.001$, Model 1). After adjustment for age and gender (Model 2), this association remained robust. After additionally adjusting for other potential confounders, the odds of decreased eGFR in the last quartile of the duration of night shift work was attenuated but remained significantly elevated with the OR $(95 \% \mathrm{Cl})$ of 1.39 (1.10 to 1.75) (Model 3). In addition, positive associations were observed between duration of night shift work (continuous), cumulative number of night shifts (continuous), and odds of decreased eGFR (bivariate), while negative associations were observed between duration of night shift work (continuous), cumulative number of night shifts (continuous), and eGFR (continuous) in the RCS models (Figure 2). However, no significant association between brightness of bedroom ambient LAN, number of times light on, and decreased eGFR was observed, regardless of whether the corresponding confounders were adjusted.

Compared with day work, elevated odds of decreased eGFR were observed in the higher exposure groups of the duration of night shift work in all subgroup analyses, except for the female group, although this association was no longer significant in some subgroups due to case numbers (Table 3 ).

\section{Sensitivity analyses}

Considering that dust, heat stress, noise, and carbon monoxide are the major occupational hazards to the current steelworkers, we further adjusted these exposures on the basis of Model 3 , and the results were similar to the previous ones (Additional file 2: Table S3). Moreover, in order to avoid the influence of the maximum value on the fitting result of restricted cubic splines, we removed the last $1 \%$ quantile of the duration of night shift work and cumulative number of night shifts, and the relationships remained comparable (Additional file 2: Figure S1).

\section{Discussion}

\section{Main results}

Our findings support that night shift work is significantly associated with a slight decline of renal function (estimated by eGFR) in steelworkers and provide additional evidence concerning dose-response relationships between duration of night shift work, cumulative number of night shifts, and eGFR among night shift workers, which have never been reported in previous studies. However, no significant association is observed between the brightness of bedroom ambient LAN and decreased eGFR.

\section{Comparison with previous findings}

Our findings are consistent with a small sample cross-sectional study conducted in 354 police officers, which concluded that night shift work was associated with decreased kidney function [23]. They also reported that percentage of hours worked on the night shift work was inversely associated with mean levels of eGFR, which was comparable to our results when it comes to the relationship between duration of night shift work, cumulative number of night shifts and eGFR. In line with our findings, another observational study also reported that small increase in albuminuria, a marker of kidney damage, was 
associated with disruption of the circadian rhythms due to shift work rather than exposure to low concentrations of nephrotoxic chemicals [24].

Notably, asynchrony between circadian clocks and external world light/dark cycle due to LAN has been associated with many negative health outcomes in previous studies. A previous largely epidemiological data showing a positive association between odds of obesity and lightness of the room slept in at night (we used the same LAN assessment method as in the above study), even after adjustment for potential confounders including night shift work [22]. However, no relationship was discovered between the brightness of bedroom ambient LAN and decreased eGFR in our study. This may be related to the overall lower level exposure of bedroom ambient LAN in our study population. In addition, considering that approximately $85 \%$ of participants are current or ever night shift workers, which is also a main cause of exposure to LAN. Therefore, the absence of brightness assessment during night work may result in bias. But this bias could be largely controlled after adjustment for the duration of night shift work, since night shift workers in this company spend most of their working hours in the central control room where the indoor environment was built according to uniform standards with the unified lighting system. Meanwhile, our results also can be supported by a finding which observed a significant association between the duration of night shift work and breast cancer (OR=1.13, 95\% $\mathrm{Cl}: 1.03-1.48)$, but not bedroom ambient light levels (OR=1.1, 95\% $\mathrm{Cl}$ : 0.9-1.2) and other lighting habits [25].

\section{Biologic plausibility}

One key assumption that explain this association is night shift work induces misalignment between the external behavioral and the endogenous molecular circadian clocks. Kidneys are organs with peripheral circadian clocks, which enable GFR to show a self-sustained rhythmicity [26]. Studies in animals and humans have shown that feeding time play a dominant role in resetting peripheral circadian oscillators, even in the absence of the synchronization of central circadian clock in the suprachiasmatic nucleus $(\mathrm{SCN})[27,28]$. Since light is the primary external world synchronizer of central circadian clock in SCN, it may be reasonable to hypothesis that chronic circadian disruption due to night shift work, other than light, may be responsible for decreased eGFR through peripheral circadian oscillators. Therefore, altered meal timing due to night shift work could explain, at least in part, the relationship between night shift work and eGFR. Moreover, the disruption of circadian sleep/wake rhythm are much more prevalent in endstage renal disease, which indicates that the displaced sleep/wake cycle due to night shift work may also be responsible for the decline of GFR [29]. In terms of sleep, it is noteworthy that in addition to sleep rhythm, sleep duration and sleep quality may also play a role in renal function [30,31]. While, after adjustment for insomnia and sleep duration, the relationship between night shift work and eGFR remained robust, which suggest that sleep rhythm may be a contributor to this association. As for the gender difference between duration of night shift work and decreased eGFR, it may be related to the protective effects of estrogens in women and/or the damaging effects of testosterone, together with unhealthier lifestyles in men, which might cause renal function to decline faster in men than in women [32]. 
Another potential mechanism by which night shift work might cause the decline of eGFR is the presence of psychological and psychosocial stressors [33]. Shift-workers are subject to heavier stress loads compared to non-shift workers [34]. Stress can cause renal vasoconstriction by stimulating the sympathetic nervous system, resulting in decreased renal plasma flow (RPF) and GFR. Besides, persistent stimulation of the hypothalamic-pituitary-adrenal (HPA) axis by external chronic stressors due to night shift work can active the sympathetic nervous system (SNS), and the activation of renal SNS may also affect the renal function through the renin-angiotensin-aldosterone system (RAAS) [35]. Moreover, the over-activation of RAAS can not only lead to an increase in intra-glomerular pressure but also to the damage of vascular endothelial cells, the activation of reactive oxygen species (ROS), and the inhibition of sympathetic hyperactivity and nitric oxide (NO), and all of them are involved in the pathophysiology of renal damage $[36,37]$.

\section{Strengths and limitations}

The major strengths of our study include the detailed shift work information, lifestyle information, health status related to CKD and large sample size. However, our research also has certain limitations. First, we are unable to infer temporality of shift work and GFR in a cross-sectional study. Second, the assessment of LAN is based on the self-reported information rather than the objective measurement of intensity. Third, we did not collect chronotype information, which may have led to a confounding bias. Fourth, those who are competent for long duration night shift work are more likely to have better physical fitness (healthy worker effect) or have tolerated to night shift work, which may underestimate the association between the exposure and outcome. Fifth, our survey population consisted of steelworkers, the vast majority of whom are male workers in north China, which limits our ability to generalize these results to the general population.

\section{Conclusion}

The increased duration of night shift work and cumulative number of night shifts among night shift workers, but not the brightness of bedroom ambient LAN, are associated with a slight decline of renal function among steelworkers. Considering the small number of female steelworkers in this study and the gender difference in renal function, the relationship between night shift work and renal function in females need to be further confirmed. Meanwhile, well-designed prospective research should be conducted with objective assessment of LAN exposure to explore the association between the intensity of LAN and renal function.

\section{Abbreviations}

LAN: Light at night; eGFR: Estimated glomerular filtration rate; GFR: Glomerular filtration rate; OR: Odds ratio; Cl: Confidence interval; ALAN: Artificial light at night; IARC: International Agency for Research on Cancer; BMI: body mass index; SCN: Suprachiasmatic nucleus; RPF: Renal plasma flow; HPA: 
Hypothalamic-pituitary-adrenal; SNS: Sympathetic nervous system; RAAS: Renin-angiotensin-aldosterone system; ROS: Reactive oxygen species; NO: Nitric oxide

\section{Declarations}

\section{Acknowledgements}

The authors would like to acknowledge all the participants and institutions.

\section{Authors' contributions}

SZ raised the study concept and drafted the manuscript. YW designed this work. ZW and HW analyzed the data. CX and QL provided inputs and revisions. JY and WG supervised the fieldwork of this project. All authors agree to submit this article.

\section{Funding}

This work was supported by the National Key R\&D Program of China (No. 2016YFC0900605).

Availability of data and materials

The datasets generated and/or analyzed during the current study are not publicly available due other analyses are proceeding but are available from the corresponding author on reasonable request.

Ethics approval and consent to participate

This research was approved by the Ethics Committee of North China University of Science and Technology (No.15006). All participants gave informed consent before taking part in this study.

\section{Consent for publication}

Not applicable.

\section{Competing interests}

The authors declare that they have no competing interests. 


\section{Author details}

${ }^{1}$ Department of Epidemiology and Health Statistics, School of Public Health, North China University of Science and Technology, Tangshan 063210, China

${ }^{2}$ Department of Epidemiology and Health Statistics, School of Public Health, Xinxiang Medical University, Xinxiang 453003, China

\section{References}

1.

James SM, Honn KA, Gaddameedhi S, Van Dongen HPA. Shift Work: Disrupted Circadian Rhythms and Sleep-Implications for Health and Well-Being. Curr Sleep Med Rep. 2017;3(2):104-12.

2.

De Bacquer D, Van Risseghem M, Clays E, Kittel F, De Backer G, Braeckman L. Rotating shift work and the metabolic syndrome: a prospective study. Int J Epidemiol. 2009;38(3):848-54.

3.

Falchi F, Cinzano P, Duriscoe D, Kyba CCM, Elvidge CD, Baugh K, Portnov BA, Rybnikova NA, Furgoni R. The new world atlas of artificial night sky brightness. Sci Adv. 2016;2(6):e1600377.

4.

Elvidge CD, Keith DM, Tuttle BT, Baugh KE. Spectral identification of lighting type and character. Sensors (Basel). 2010;10(4):3961-88.

5.

Yang C, Wang H, Zhao X, Matsushita K, Coresh J, Zhang L, Zhao MH. CKD in China: Evolving Spectrum and Public Health Implications. Am J Kidney Dis. 2019.

6.

Firsov D, Bonny O. Circadian rhythms and the kidney. Nat Rev Nephrol. 2018;14(10):626-35.

7.

Solocinski K, Gumz ML. The Circadian Clock in the Regulation of Renal Rhythms. J Biol Rhythms. 2015;30(6):470-86.

8.

Callaway E, Ledford H. Medicine Nobel awarded for work on circadian clocks. Nature. 2017;550(7674):18. 9.

Shan Z, Li Y, Zong G, Guo Y, Li J, Manson JE, Hu FB, Willett WC, Schernhammer ES, Bhupathiraju SN. Rotating night shift work and adherence to unhealthy lifestyle in predicting risk of type 2 diabetes: results from two large US cohorts of female nurses. BMJ. 2018;363:k4641.

10.

Vetter C, Dashti HS, Lane JM, Anderson SG, Schernhammer ES, Rutter MK, Saxena R, Scheer FAJL. Night Shift Work, Genetic Risk, and Type 2 Diabetes in the UK Biobank. Diabetes Care. 2018;41(4):762-9. 
11.

Sun M, Feng W, Wang F, Li P, Li Z, Li M, Tse G, Vlaanderen J, Vermeulen R, Tse LA. Meta-analysis on shift work and risks of specific obesity types. Obes Rev. 2018;19(1):28-40.

12.

Wang D, Ruan W, Chen Z, Peng Y, Li W. Shift work and risk of cardiovascular disease morbidity and mortality: A dose-response meta-analysis of cohort studies. Eur J Prev Cardiol. 2018;25(12):1293-302. 13.

Carcinogenicity of night shift work. The Lancet Oncology. 2019;20(8):1058-9.

14.

Garcia-Saenz A, Sanchez de Miguel A, Espinosa A, Valentin A, Aragones N, Llorca J, Amiano P, Martin Sanchez V, Guevara M, Capelo R, et al. Evaluating the Association between Artificial Light-at-Night Exposure and Breast and Prostate Cancer Risk in Spain (MCC-Spain Study). Environ Health Perspect. 2018;126(4):047011.

15.

Fonken LK, Nelson RJ. The effects of light at night on circadian clocks and metabolism. Endocr Rev. $2014,35(4): 648-70$.

16.

West AC, Smith L, Ray DW, Loudon ASI, Brown TM, Bechtold DA. Misalignment with the external light environment drives metabolic and cardiac dysfunction. Nature communications. 2017;8(1):417. 17.

Zhang S, Wang Y, Wang Z, Wang H, Xue C, Li Q, Guan W, Yuan J. Rotating night shift work and nonalcoholic fatty liver disease among steelworkers in China: a cross-sectional survey. Occup Environ Med. 2020:oemed-2019-106220.

18.

Levey AS, Stevens LA, Schmid CH, Zhang YL, Castro AF 3rd, Feldman HI, Kusek JW, Eggers P, Van Lente F, Greene T, et al. A new equation to estimate glomerular filtration rate. Ann Intern Med. 2009;150(9):60412.

19.

Webster AC, Nagler EV, Morton RL, Masson P. Chronic Kidney Disease. Lancet. 2017;389(10075):123852.

20.

Wang F, Zhang L, Zhang Y, Zhang B, He Y, Xie S, Li M, Miao X, Chan EY, Tang JL, et al. Meta-analysis on night shift work and risk of metabolic syndrome. Obes Rev. 2014;15(9):709-20.

21.

Lie JA, Kjuus H, Zienolddiny S, Haugen A, Stevens RG, Kjaerheim K. Night work and breast cancer risk among Norwegian nurses: assessment by different exposure metrics. Am J Epidemiol. 2011;173(11):1272-9.

22.

McFadden E, Jones ME, Schoemaker MJ, Ashworth A, Swerdlow AJ. The relationship between obesity and exposure to light at night: cross-sectional analyses of over 100,000 women in the Breakthrough 
Generations Study. Am J Epidemiol. 2014;180(3):245-50.

23.

Charles LE, Gu JK, Fekedulegn D, Andrew ME, Violanti JM, Burchfiel CM. Association between shiftwork and glomerular filtration rate in police officers. J Occup Environ Med. 2013;55(11):1323-8.

24.

Boogaard PJ, Caubo ME. Increased albumin excretion in industrial workers due to shift work rather than to prolonged exposure to low concentrations of chlorinated hydrocarbons. Occup Environ Med. 1994;51(9):638-41.

25.

Davis S, Mirick DK, Stevens RG. Night shift work, light at night, and risk of breast cancer. J Natl Cancer Inst. 2001;93(20):1557-62.

26.

Voogel AJ, Koopman MG, Hart AA, van Montfrans GA, Arisz L. Circadian rhythms in systemic hemodynamics and renal function in healthy subjects and patients with nephrotic syndrome. Kidney Int. 2001;59(5):1873-80.

27.

Schibler U, Ripperger J, Brown SA. Peripheral circadian oscillators in mammals: time and food. J Biol Rhythms. 2003;18(3):250-60.

28.

Wehrens SMT, Christou S, Isherwood C, Middleton B, Gibbs MA, Archer SN, Skene DJ. Johnston JD: Meal Timing Regulates the Human Circadian System. Curr Biol. 2017;27(12):1768-75.e1763. 29.

Koch BC, Nagtegaal JE, Kerkhof GA, ter Wee PM. Circadian sleep-wake rhythm disturbances in end-stage renal disease. Nat Rev Nephrol. 2009;5(7):407-16.

30.

McMullan CJ, Curhan GC, Forman JP. Association of short sleep duration and rapid decline in renal function. Kidney Int. 2016;89(6):1324-30.

31.

Yamamoto R, Shinzawa M, Isaka Y, Yamakoshi E, Imai E, Ohashi Y, Hishida A. Sleep Quality and Sleep Duration with CKD are Associated with Progression to ESKD. Clin J Am Soc Nephrol. 2018;13(12):182532 .

32.

Carrero JJ, Hecking M, Chesnaye NC, Jager KJ. Sex and gender disparities in the epidemiology and outcomes of chronic kidney disease. Nat Rev Nephrol. 2018;14(3):151-64.

33.

Thomas C, Power C. Shift work and risk factors for cardiovascular disease: a study at age 45 years in the 1958 British birth cohort. Eur J Epidemiol. 2010;25(5):305-14.

34.

Roskoden FC, Kruger J, Vogt LJ, Gartner S, Hannich HJ, Steveling A, Lerch MM, Aghdassi AA. Physical Activity, Energy Expenditure, Nutritional Habits, Quality of Sleep and Stress Levels in Shift-Working Health 
Care Personnel. PLoS One. 2017;12(1):e0169983.

35.

DiBona GF. Nervous kidney. Interaction between renal sympathetic nerves and the renin-angiotensin system in the control of renal function. Hypertension. 2000;36(6):1083-8.

36.

Oberleithner $\mathrm{H}$. Aldosterone makes human endothelium stiff and vulnerable. Kidney Int. 2005;67(5):1680-2.

37.

Ishigaki S, Ohashi N, Isobe S, Tsuji N, Iwakura T, Ono M, Sakao Y, Tsuji T, Kato A, Miyajima H, et al. Impaired endogenous nighttime melatonin secretion relates to intrarenal renin-angiotensin system activation and renal damage in patients with chronic kidney disease. Clin Exp Nephrol. 2016;20(6):87884.

\section{Tables}

Table 1 Basic characteristics according to eGFR status 


\begin{tabular}{|c|c|c|c|c|}
\hline \multirow[t]{2}{*}{ Variables } & \multirow{2}{*}{$\begin{array}{l}\text { Overall } \\
(N=6869)\end{array}$} & \multirow{2}{*}{$\begin{array}{c}\text { Without decreased eGFR } \\
(\mathrm{n}=5860)\end{array}$} & \multirow{2}{*}{$\begin{array}{c}\text { With decreased eGFR } \\
(n=1009)\end{array}$} & \multirow[b]{2}{*}{$P$ value } \\
\hline & & & & \\
\hline Age (year) & $44.2 \pm 8.0$ & $43.6 \pm 8.1$ & $47.9 \pm 6.3$ & $<0.001$ \\
\hline \multicolumn{5}{|l|}{ Sex, n (\%) } \\
\hline Male & $6283(91.5)$ & $5370(91.6)$ & $913(90.5)$ & 0.226 \\
\hline Female & $586(8.5)$ & $490(8.4)$ & $96(9.5)$ & \\
\hline Ethnicity & & & & 0.494 \\
\hline Han & $6727(97.9)$ & $5736(97.9)$ & $991(98.2)$ & \\
\hline Others & $142(2.1)$ & $124(2.1)$ & $18(1.8)$ & \\
\hline BMI $\left(\mathrm{kg} / \mathrm{m}^{2}\right), \mathrm{n}(\%)$ & $25.2 \pm 3.4$ & $25.1 \pm 3.4$ & $25.7 \pm 3.3$ & $<0.001$ \\
\hline Smoking status, n (\%) & & & & 0.196 \\
\hline Never & $2817(41.0)$ & $2409(41.1)$ & $408(40.4)$ & \\
\hline Ever & $549(8.0)$ & $454(7.6)$ & $95(9.4)$ & \\
\hline Current & $3503(51.0)$ & $2997(51.1)$ & $506(50.2)$ & \\
\hline Alcohol consumption, n (\%) & & & & 0.233 \\
\hline Never & $3936(57.3)$ & $3353(57.2)$ & $583(57.8)$ & \\
\hline Ever & $393(5.7)$ & $325(5.6)$ & $68(6.7)$ & \\
\hline Current & $2540(37.0)$ & $2182(37.2)$ & $358(35.5)$ & \\
\hline Education level, n (\%) & & & & $<0.001$ \\
\hline Primary or illiterate & $86(1.3)$ & $71(1.2)$ & $15(1.5)$ & \\
\hline Middle or high school & $5326(77.5)$ & $4483(76.5)$ & $843(83.6)$ & \\
\hline University or college & $1457(21.2)$ & $1306(22.3)$ & $151(15.0)$ & \\
\hline Physical activity, n (\%) & & & & 0.270 \\
\hline Low & $80(1.2)$ & $70(1.2)$ & $10(1.0)$ & \\
\hline Moderate & $522(7.6)$ & $457(7.8)$ & $65(6.4)$ & \\
\hline High & $6267(91.2)$ & $5333(91.0)$ & $934(92.6)$ & \\
\hline Duration of night shift work (years) & & & & $<0.001$ \\
\hline Day work & $1029(15.0)$ & $896(15.3)$ & $133(13.2)$ & \\
\hline Q1 (1-12) & $1471(21.4)$ & $1317(22.5)$ & $154(15.3)$ & \\
\hline Q2 (13-20) & $1495(21.8)$ & $1328(22.7)$ & $167(16.6)$ & \\
\hline Q3 (21-28) & $1314(19.1)$ & $1102(18.8)$ & $212(21.0)$ & \\
\hline Q4 (29-43) & $1560(22.7)$ & $1217(20.8)$ & $343(34.0)$ & \\
\hline Brightness of bedroom ambient LAN, n (\%) & & & & 0.856 \\
\hline Darkest level & $3782(55.1)$ & $3222(55.0)$ & $560(55.5)$ & \\
\hline Middle level & $2276(33.1)$ & 1949 (33.2) & $327(32.4)$ & \\
\hline Lightest level & $811(11.8)$ & $689(11.8)$ & $122(12.1)$ & \\
\hline Number of times light on (times/night), n (\%) & & & & 0.645 \\
\hline 0 & $4194(61.1)$ & $3584(61.2)$ & $610(60.5)$ & \\
\hline 1 & $2172(31.6)$ & $1854(31.6)$ & $318(31.5)$ & \\
\hline$\geq 2$ & $503(7.3)$ & $422(7.2)$ & $81(8.0)$ & \\
\hline Sleep duration $(\mathrm{h})$ & $6.8 \pm 1.2$ & $6.8 \pm 1.2$ & $6.8 \pm 1.2$ & 0.005 \\
\hline Insomnia, n (\%) & & & & 0.990 \\
\hline No & $4560(66.4)$ & $3890(66.4)$ & $670(66.4)$ & \\
\hline Yes & $2309(33.6)$ & $1970(33.6)$ & $339(33.6)$ & \\
\hline Diabetes, n (\%) & & & & 0.150 \\
\hline No & 6147 (89.5) & 5257 (89.7) & $890(88.2)$ & \\
\hline Yes & $722(10.5)$ & $603(10.3)$ & $119(11.8)$ & \\
\hline Fasting blood glucose $(\mathrm{mmol} / \mathrm{L})$ & $5.8(5.4 \sim 6.3)$ & $5.8(5.4 \sim 6.3)$ & $5.9(5.5 \sim 6.4)$ & $<0.001$ \\
\hline
\end{tabular}


Hypertension, n (\%)

$<0.001$

\begin{tabular}{|c|c|c|c|c|}
\hline No & $5109(74.4)$ & 4447 (75.9) & $662(65.6)$ & \\
\hline Yes & $1760(25.6)$ & $1413(24.1)$ & $347(34.4)$ & \\
\hline Systolic blood pressure (mmHg) & $129.0 \pm 16.0$ & $128.5 \pm 15.8$ & $131.8 \pm 17.2$ & $<0.001$ \\
\hline Diastolic blood pressure (mmHg) & $82.5 \pm 10.4$ & $82.2 \pm 10.2$ & $84.7 \pm 11.0$ & $<0.001$ \\
\hline Dyslipidemia, n (\%) & & & & $<0.001$ \\
\hline No & 4074 (59.3) & $3541(60.4)$ & $533(52.8)$ & \\
\hline Yes & 2795 (40.7) & 2319 (39.6) & $476(47.2)$ & \\
\hline a Proteinuria (mg/dl) & & & & $<0.001$ \\
\hline A1 $(<30)$ & $6745(98.2)$ & $5772(98.5)$ & $973(96.4)$ & \\
\hline A2-A3 ( $\geq 30)$ & $124(1.8)$ & $88(1.5)$ & $36(3.6)$ & \\
\hline
\end{tabular}

$P$-values were from Pearson's chi-square test for categorical variables and Student's t test or Wilcoxon Scores (Rank Sums) for continuous variables. ${ }^{a}$ Categories of proteinuria were defined as negative and trace (proteinuria<30 mg/dl, A1), 1+ (proteinuria: 30-300 mg/dl, A2), and 2+ (proteinuria $>300 \mathrm{mg} / \mathrm{dl}, \mathrm{A} 3$ ).

Table 2 Multivariable logistic regression analyses for association between night shift work, bedroom ambient light level, and decreased eGFR

\begin{tabular}{|c|c|c|c|c|c|}
\hline \multirow[t]{2}{*}{ Exposure metrics } & \multicolumn{2}{|c|}{ Decreased eGFR $\left(\mathrm{mL} / \mathrm{min} / 1.73 \mathrm{~m}^{2}\right)$} & \multicolumn{3}{|c|}{ OR $(95 \%$ CI $)$} \\
\hline & No $(\geq 90)$ & Yes $(<90)$ & Model 1 & Model 2 & Model 3 \\
\hline \multicolumn{6}{|l|}{ Duration of night shift (years) } \\
\hline Day work & $896(87.1)$ & $133(13.2)$ & 1.00 & 1.00 & 1.00 \\
\hline Q1 (1-12) & 1317 (89.5) & $154(10.5)$ & $0.79(0.61$ to 1.01$)$ & $1.10(0.85$ to 1.42$)$ & 1.07 (0.82 to 1.38$)$ \\
\hline Q2 (13-20) & $1328(88.8)$ & $167(11.2)$ & 0.84 (0.66 to 1.08$)$ & $1.12(0.87$ to 1.44$)$ & 1.06 (0.82 to 1.37$)$ \\
\hline Q3 (21-28) & $1102(83.9)$ & $212(16.1)$ & 1.29 (1.02 to 1.63$)$ & 1.32 (1.04 to 1.68$)$ & 1.29 (1.01 to 1.64$)$ \\
\hline Q4 (29-43) & $1217(78.0)$ & $343(22.0)$ & 1.89 (1.52 to 2.36$)$ & 1.40 (1.12 to 1.75$)$ & 1.39 (1.10 to 1.75$)$ \\
\hline$P$ for trend & & & $<0.001$ & $<0.001$ & 0.001 \\
\hline \multicolumn{6}{|c|}{ Brightness of bedroom ambient LAN } \\
\hline Darkest level & $3222(85.2)$ & $560(14.8)$ & 1.00 & 1.00 & 1.00 \\
\hline Middle level & 1949 (85.6) & $327(14.4)$ & $0.96(0.83$ to 1.12$)$ & 0.91 (0.78 to 1.06$)$ & 0.90 (0.77 to 1.05$)$ \\
\hline Lightest level & $689(85.0)$ & $122(15.0)$ & 0.99 (0.80 to 1.23$)$ & 0.97 (0.78 to 1.20$)$ & $0.94(0.75$ to 1.17$)$ \\
\hline \multicolumn{6}{|c|}{ Number of times light on (times/night) } \\
\hline 0 & 3584 (85.5) & $610(60.5)$ & 1.00 & 1.00 & 1.00 \\
\hline 1 & $1854(31.6)$ & $318(31.5)$ & $0.98(0.85$ to 1.14$)$ & 0.97 (0.84 to 1.13$)$ & 0.96 (0.83 to 1.12$)$ \\
\hline$\geq 2$ & $422(83.9)$ & $81(16.1)$ & 1.07 (0.83 to 1.39$)$ & $1.02(0.79$ to 1.32$)$ & $1.00(0.77$ to 1.29$)$ \\
\hline
\end{tabular}

Model 1: unadjusted; Model 2: adjusted for age and gender; Model 3: further adjusted for BMI ( $<25$, 25-30, or $\geq 30 \mathrm{~kg} / \mathrm{m}^{2}$ ), ethnicity, smoking status, drinking status, education level, physical activity, sleep duration ( $<7$, or $\geq 7$ hours), insomnia, diabetes, hypertension, and dyslipidemia.

Table 3 Association between duration of night shift work and decreased eGFR stratified by sex, BMI, brightness of bedroom ambient LAN, diabetes, hypertension, dyslipidemia, insomnia, and short sleep duration. 


\begin{tabular}{|c|c|c|c|c|c|c|}
\hline \multirow[t]{2}{*}{ Groups } & \multicolumn{4}{|c|}{ Duration of night shift (years) } & \multirow[b]{2}{*}{ Q4 (29-43) } & \multirow[b]{2}{*}{$\begin{array}{c}P \text { for } \\
\text { interaction }\end{array}$} \\
\hline & $\begin{array}{c}\text { Day } \\
\text { work }\end{array}$ & Q1 (1-12) & Q2 (13-20) & Q3 (21-28) & & \\
\hline Sex & 0.098 & & & & & \\
\hline Male, OR (95\% CI) & 1.00 & $\begin{array}{c}1.02(0.77 \text { to } \\
1.34)\end{array}$ & $\begin{array}{c}1.08(0.82 \text { to } \\
1.41)\end{array}$ & $\begin{array}{c}1.38 \text { (1.06 to } \\
1.78)\end{array}$ & $\begin{array}{c}1.43 \text { (1.12 to } \\
1.82)\end{array}$ & \\
\hline n without decreased eGFR & $\begin{array}{c}796 \\
(87.5)\end{array}$ & 1219 (90.4) & $1216(89.1)$ & 990 (83.5) & $1149(78.0)$ & \\
\hline $\mathrm{n}$ with decreased eGFR & $\begin{array}{c}114 \\
(12.5)\end{array}$ & $130(9.6)$ & 149 (10.9) & 195 (16.5) & $325(22.1)$ & \\
\hline Female, OR (95\% CI) & 1.00 & $\begin{array}{c}1.06(0.51 \text { to } \\
2.22)\end{array}$ & $\begin{array}{c}0.70(0.32 \text { to } \\
1.53)\end{array}$ & $\begin{array}{c}0.61(0.28 \text { to } \\
1.32)\end{array}$ & $\begin{array}{c}0.86(0.38 \text { to } \\
1.93)\end{array}$ & \\
\hline $\mathrm{n}$ without decreased eGFR & $\begin{array}{c}100 \\
(84.0)\end{array}$ & $98(80.3)$ & $112(86.2)$ & $112(86.8)$ & $68(79.1)$ & \\
\hline $\mathrm{n}$ with decreased eGFR & $19(16.0)$ & $24(19.7)$ & $18(13.9)$ & $17(13.2)$ & $18(20.9)$ & \\
\hline BMI & 0.878 & & & & & \\
\hline$<25$, OR $(95 \%$ CI) & 1.00 & $\begin{array}{c}1.21 \text { (0.83 to } \\
1.77)\end{array}$ & $\begin{array}{c}1.38 \text { (0.95 to } \\
2.01)\end{array}$ & $\begin{array}{c}1.49 \text { (1.04 to } \\
2.13)\end{array}$ & $\begin{array}{c}1.60(1.14 \text { to } \\
2.23)\end{array}$ & \\
\hline n without decreased eGFR & $\begin{array}{c}521 \\
(89.5)\end{array}$ & 687 (90.6) & 641 (89.3) & $556(85.8)$ & $632(80.6)$ & \\
\hline $\mathrm{n}$ with decreased eGFR & $60(10.5)$ & $71(9.4)$ & 77 (10.7) & $92(14.2)$ & $152(19.4)$ & \\
\hline$\geq 25$, OR $(95 \%$ CI $)$ & 1.00 & $\begin{array}{l}0.95(0.67 \text { to } \\
1.36)\end{array}$ & $\begin{array}{c}0.87(0.62 \text { to } \\
1.24)\end{array}$ & $\begin{array}{c}1.13(0.81 \text { to } \\
1.57)\end{array}$ & $\begin{array}{c}1.21(0.88 \text { to } \\
1.67)\end{array}$ & \\
\hline $\mathrm{n}$ without decreased eGFR & $\begin{array}{c}384 \\
(84.0)\end{array}$ & $630(88.4)$ & $687(88.4)$ & $546(82.0)$ & $585(75.4)$ & \\
\hline n with decreased eGFR & $73(16.0)$ & $83(11.6)$ & $90(11.6)$ & $120(18.0)$ & $191(24.6)$ & \\
\hline $\begin{array}{l}\text { Brightness of bedroom ambient } \\
\text { LAN }\end{array}$ & 0.926 & & & & & \\
\hline Darkest level, OR (95\% CI) & 1.00 & $\begin{array}{c}1.07 \text { (0.74 to } \\
1.54)\end{array}$ & $\begin{array}{c}1.09 \text { (0.76 to } \\
1.55)\end{array}$ & $\begin{array}{c}1.38 \text { ( } 0.98 \text { to } \\
1.95)\end{array}$ & $\begin{array}{c}1.47 \text { (1.06 to } \\
2.05)\end{array}$ & \\
\hline n without decreased eGFR & $\begin{array}{c}424 \\
(87.6)\end{array}$ & $714(89.4)$ & 799 (88.7) & $632(83.2)$ & 653 (77.9) & \\
\hline $\mathrm{n}$ with decreased eGFR & $60(12.4)$ & 85 (10.6) & $102(11.3)$ & $128(16.8)$ & $185(22.1)$ & \\
\hline $\begin{array}{l}\text { Middle or Lightest level, OR (95\% } \\
\text { CI) }\end{array}$ & 1.00 & $\begin{array}{c}1.08 \text { ( } 0.75 \text { to } \\
1.56)\end{array}$ & $\begin{array}{c}1.08(0.74 \text { to } \\
1.58)\end{array}$ & $\begin{array}{c}1.24(0.87 \text { to } \\
1.76)\end{array}$ & $\begin{array}{c}1.33 \text { ( } 0.97 \text { to } \\
1.84)\end{array}$ & \\
\hline $\mathrm{n}$ without decreased eGFR & $\begin{array}{c}472 \\
(86.6)\end{array}$ & 603 (89.7) & $529(89.1)$ & $470(84.8)$ & $564(78.1)$ & \\
\hline $\mathrm{n}$ with decreased eGFR & $73(13.4)$ & $69(10.3)$ & $69(10.3)$ & $84(15.2)$ & 158 (21.9) & \\
\hline Diabetes & 0.763 & & & & & \\
\hline No, OR (95\% CI) & 1.00 & $\begin{array}{c}1.02(0.78 \text { to } \\
1.34)\end{array}$ & $\begin{array}{c}1.04(0.80 \text { to } \\
1.36)\end{array}$ & $\begin{array}{c}1.26 \text { ( } 0.97 \text { to } \\
1.62)\end{array}$ & $\begin{array}{c}1.31 \text { (1.02 to } \\
1.67)\end{array}$ & \\
\hline n without decreased eGFR & $\begin{array}{c}807 \\
(87.1)\end{array}$ & $1213(89.9)$ & $1218(88.7)$ & 989 (83.8) & $1030(78.2)$ & \\
\hline $\mathrm{n}$ with decreased eGFR & $\begin{array}{c}120 \\
(12.9)\end{array}$ & $137(10.2)$ & 155 (11.3) & $191(16.2)$ & $287(21.8)$ & \\
\hline Yes, OR (95\% CI) & 1.00 & $\begin{array}{c}1.61(0.70 \text { to } \\
3.70)\end{array}$ & $\begin{array}{c}1.33(0.53 \text { to } \\
3.32)\end{array}$ & $\begin{array}{c}1.83 \text { (0.81 to } \\
4.14)\end{array}$ & $\begin{array}{c}2.02(0.99 \text { to } \\
4.11)\end{array}$ & \\
\hline $\mathrm{n}$ without decreased eGFR & $89(87.3)$ & $104(86.0)$ & $110(90.2)$ & $113(84.3)$ & 187 (76.9) & \\
\hline n with decreased eGFR & $13(12.8)$ & $17(14.1)$ & $12(9.8)$ & $21(15.7)$ & $56(23.1)$ & \\
\hline Hypertension & 0.536 & & & & & \\
\hline No, OR (95\% CI) & 1.00 & $\begin{array}{c}1.05 \text { ( } 0.77 \text { to } \\
1.43)\end{array}$ & $\begin{array}{c}0.99(0.73 \text { to } \\
1.34)\end{array}$ & $\begin{array}{c}1.19(0.89 \text { to } \\
1.60)\end{array}$ & $\begin{array}{c}1.40 \text { (1.06 to } \\
1.86)\end{array}$ & \\
\hline $\mathrm{n}$ without decreased eGFR & $\begin{array}{c}684 \\
(88.4)\end{array}$ & $1064(90.7)$ & $1061(90.4)$ & $828(86.1)$ & 810 (78.9) & \\
\hline $\mathrm{n}$ with decreased eGFR & $90(11.6)$ & $109(9.3)$ & $113(9.6)$ & 134 (13.9) & $216(21.1)$ & \\
\hline Yes, OR (95\% CI) & 1.00 & $\begin{array}{l}1.08(0.67 \text { to } \\
1.73)\end{array}$ & $\begin{array}{l}1.27(0.80 \text { to } \\
2.02)\end{array}$ & $\begin{array}{l}1.53(0.99 \text { to } \\
2.36)\end{array}$ & $\begin{array}{l}1.37(0.92 \text { to } \\
2.05)\end{array}$ & \\
\hline $\mathrm{n}$ without decreased eGFR & $\begin{array}{c}212 \\
(83.1)\end{array}$ & $253(84.9)$ & $267(81.2)$ & $274(77.8)$ & $407(76.2)$ & \\
\hline $\mathrm{n}$ with decreased eGFR & $43(16.9)$ & $45(15.1)$ & $54(16.8)$ & $78(22.2)$ & 127 (23.8) & \\
\hline Dyslipidemia & 0.399 & & & & & \\
\hline
\end{tabular}




\begin{tabular}{|c|c|c|c|c|c|}
\hline No, OR (95\% CI) & 1.00 & $\begin{array}{c}0.89 \text { (0.63 to } \\
1.27)\end{array}$ & $\begin{array}{c}1.07 \text { ( } 0.76 \text { to } \\
1.51)\end{array}$ & $\begin{array}{c}1.24 \text { (0.90 to } \\
1.72)\end{array}$ & $\begin{array}{c}1.40(1.04 \text { to } \\
1.90)\end{array}$ \\
\hline $\mathrm{n}$ without decreased eGFR & $\begin{array}{c}562 \\
(88.0)\end{array}$ & $829(91.9)$ & 756 (89.7) & $672(85.8)$ & $722(79.6)$ \\
\hline $\mathrm{n}$ with decreased eGFR & $77(12.1)$ & $73(8.1)$ & $87(10.3)$ & $111(14.2)$ & $185(20.4)$ \\
\hline Yes, OR $(95 \%$ CI $)$ & 1.00 & $\begin{array}{c}1.27 \text { (0.87 to } \\
1.87)\end{array}$ & $\begin{array}{c}1.05(0.71 \text { to } \\
1.54)\end{array}$ & $\begin{array}{c}1.35 \text { (0.93 to } \\
1.96)\end{array}$ & $\begin{array}{c}1.36(0.96 \text { to } \\
1.94)\end{array}$ \\
\hline n without decreased eGFR & $\begin{array}{c}334 \\
(85.6)\end{array}$ & $488(85.8)$ & $572(87.7)$ & $430(81.0)$ & $495(75.8)$ \\
\hline n with decreased eGFR & $56(14.4)$ & $81(14.2)$ & $80(12.3)$ & $101(19.0)$ & $158(24.2)$ \\
\hline Insomnia & 0.691 & & & & \\
\hline No, OR $(95 \%$ CI) & 1.00 & $\begin{array}{c}0.99 \text { (0.73 to } \\
1.36)\end{array}$ & $\begin{array}{c}1.00(0.74 \text { to } \\
1.34)\end{array}$ & $\begin{array}{c}1.18 \text { (0.88 to } \\
1.57)\end{array}$ & $\begin{array}{c}1.38(1.04 \text { to } \\
1.82)\end{array}$ \\
\hline n without decreased eGFR & $\begin{array}{c}614 \\
(86.6)\end{array}$ & $868(89.6)$ & $881(89.2)$ & $750(84.4)$ & 777 (77.3) \\
\hline n with decreased eGFR & $95(13.4)$ & $101(10.4)$ & $107(10.8)$ & $139(15.6)$ & $228(22.7)$ \\
\hline Yes, OR $(95 \%$ CI $)$ & 1.00 & $\begin{array}{c}0.85 \text { (0.53 to } \\
1.35)\end{array}$ & $\begin{array}{c}0.99(0.66 \text { to } \\
1.49)\end{array}$ & $\begin{array}{c}1.27 \text { (0.86 to } \\
1.89)\end{array}$ & $\begin{array}{c}1.26(0.83 \text { to } \\
1.83)\end{array}$ \\
\hline n without decreased eGFR & $\begin{array}{c}282 \\
(88.1)\end{array}$ & $449(89.4)$ & $447(88.2)$ & $352(82.8)$ & $440(79.3)$ \\
\hline $\mathrm{n}$ with decreased eGFR & $38(11.9)$ & $53(10.6)$ & $60(11.8)$ & $73(17.2)$ & $115(20.7)$ \\
\hline Short sleep duration & 0.925 & & & & \\
\hline No, OR (95\% CI) & 1.00 & $\begin{array}{c}0.84(0.56 \text { to } \\
1.26)\end{array}$ & $\begin{array}{c}0.99(0.70 \text { to } \\
1.40)\end{array}$ & $\begin{array}{c}1.25(0.90 \text { to } \\
1.73)\end{array}$ & $\begin{array}{c}1.23(0.90 \text { to } \\
1.73)\end{array}$ \\
\hline n without decreased eGFR & $\begin{array}{c}309 \\
(85.8)\end{array}$ & $562(88.8)$ & $610(88.0)$ & $570(82.7)$ & $734(77.3)$ \\
\hline $\mathrm{n}$ with decreased eGFR & $51(14.2)$ & $71(11.2)$ & $83(12.0)$ & $119(17.3)$ & $216(22.7)$ \\
\hline Yes, OR (95\% CI) & 1.00 & $\begin{array}{c}1.00(0.71 \text { to } \\
1.40)\end{array}$ & $\begin{array}{c}0.99 \text { (0.72 to } \\
1.38)\end{array}$ & $\begin{array}{c}1.16(0.84 \text { to } \\
1.62)\end{array}$ & $\begin{array}{c}1.36(0.98 \text { to } \\
1.89)\end{array}$ \\
\hline n without decreased eGFR & $\begin{array}{c}587 \\
(87.7)\end{array}$ & $755(90.1)$ & $718(89.5)$ & $532(85.1)$ & $483(79.2)$ \\
\hline $\mathrm{n}$ with decreased eGFR & $82(12.3)$ & $83(9.9)$ & $84(10.5)$ & 93 (14.9) & $127(20.8)$ \\
\hline
\end{tabular}

$P$ values for interaction were estimated using a log likelihood ratio test to compare models with and without cross-product interaction terms; The variables adjusted in each subgroup were the same as Model 3 in Table 2 except for the stratification variable.

\section{Figures}


8705 workers were included in the annual legally required health examination plan in 2017

7661 workers included with informed consent

6869 participants included

Figure 1

Flow chart of selection of participants. 

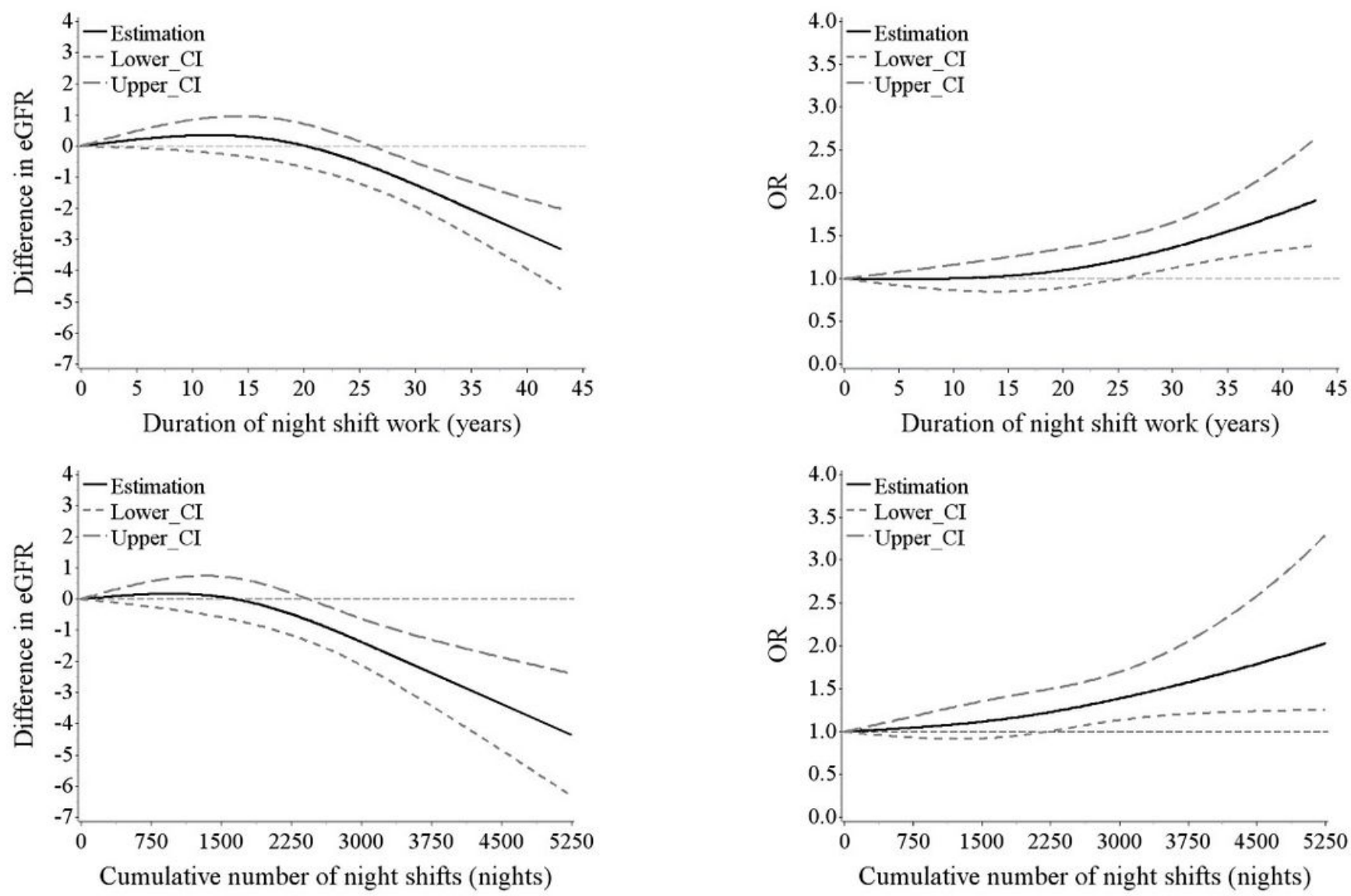

Figure 2

The association between duration of night shift work (continuous), cumulative number of night shifts (continuous), and eGFR. "Difference in eGFR" indicates difference in eGFR $(\mathrm{mL} / \mathrm{min} / 1.73 \mathrm{~m} 2)$ where the reference value for duration of night shift work or cumulative number of night shifts is 0 (day work). "Cl" indicates $95 \%$ confidence interval. Adjusted for age, gender, BMI $(<25,25-30$, or $\geq 30 \mathrm{~kg} / \mathrm{m} 2)$, ethnicity, smoking status, drinking status, education level, physical activity, brightness of bedroom ambient LAN, number of times light on, sleep duration ( $<7$, or $\geq 7$ hours), insomnia, diabetes, hypertension, and dyslipidemia.

\section{Supplementary Files}

This is a list of supplementary files associated with this preprint. Click to download.

- Additionalmaterial.docx 